\title{
UNDERGRADUATE WRITING ASSIGNMENTS IN ENGINEERING: TRACKING ATTRIBUTE 7 IN TWO ACCREDITATION CYCLES
}

\author{
Kathryn Marcynuk, Vanier Scholar, and Anne Parker, Ph.D. \\ Centre for Engineering Professional Practice and Engineering Education \\ University of Manitoba \\ Anne.Parker@umanitoba.ca; ummarcyk@myumanitoba.ca
}

\begin{abstract}
This paper reports on two iterations of our study of course syllabi in the Faculty of Engineering, University of Manitoba. The first iteration was part of a national study investigating the writing demands placed on students in a variety of disciplines, including those in the Social Sciences and the Humanities as well as Engineering. This first iteration followed an accreditation visit and the Faculty's introduction of the C.E.A.B. graduate attributes and outcome-based assessment. Although one would expect Engineering to have far fewer written assignments than these other disciplines, such was not always the case. For example, the national study captured results for Political Science that closely matched those for Mechanical Engineering; Political Science students typically wrote, on average, 2.3 written assignments in year 2 of their program, 2.4 written assignments in year 3 , and 4.2 written assignments in year 4, while Mechanical Engineering students wrote 4, 3 and 4.2 written assignments in those same years.

Such a finding suggested that more writing was happening in the Faculty of Engineering than we might realize - and quite apart from that done in the mandatory communication class. So, our second iteration of the study followed another accreditation cycle, but this time we focused solely on the Faculty of Engineering at the University of Manitoba. In this second iteration, our goal was to refresh the data so that we could clarify how Attribute 7, "communication skills," is being met in the Faculty of Engineering at the University of Manitoba.
\end{abstract}

Keywords: Attribute 7, communication skills, undergraduate courses, writing assignments, Engineering.

\subsection{INTRODUCTION}

The earlier study was a national study originating at the University of Alberta with Dr. Roger Graves as Principal Investigator. There were 11 institutions and more than 36 departments who participated. The objective was to see what kinds and how many written assignments our undergraduate students do in a course or a department. Our hope was that conversations about writing could then be initiated about how writing is taught and supported within departments.

The first iteration of our study collected course syllabi from the departments of Electrical and Computer Engineering, Civil Engineering and Mechanical Engineering [4]. We looked specifically for Attribute 7 in 133 courses and, of these, 95 identified it. We looked at the total number of assignments (by year in the program) for each of these departments; the average number of written assignments in each course; the types of assignments; and the kind of feedback provided (summative or formative).

However, we found that we couldn't definitively say much about how a course included Attribute 7 or even how it was assessed; unfortunately, those details were missing from the course syllabi. Indeed, the most common designation was simply "assignments," followed by "lab reports" and "projects," generic descriptors that did not specify assignment requirements or how the writing would be assessed. Nor was there any hint as to how the assignment measured students' communicative competence.

Our second iteration of the study showed that Attribute 7 is still included in many course syllabi. As well, most programs included fewer assignments early in the program but this number increased later in the program, a signal that some scaffolding did indeed occur. Furthermore, similar to the earlier iteration of the 
study, the trend to give a greater weighting to the communication elements in these later assignments was also evident.

Therefore, this kind of study is significant for a number of different reasons. For one thing, our industry stakeholders have repeatedly emphasized the importance of communication skills [1]. For another, scholars like Reave have likewise stressed that a "welldesigned" program in Engineering should provide a solid foundation in communication skills [5]. Finally, engineering educators have also urged that engineering curricula need to integrate communication and engineering such that what we teach mirrors what happens in practice [3], [4]. To do so, instantiating written assignments throughout an engineering program will fulfill these various needs while recognizing that writing is a practice-based skill that, similar to learning a musical instrument [3], requires scaffolding and iteration.

\subsection{THE FINDINGS}

In this study we collected course syllabi from the four Engineering departments at the University of Manitoba: Biosystems Engineering, Civil Engineering, Electrical \& Computer Engineering (ECE), and Mechanical Engineering. The total number of course syllabi collected for this survey is shown in Table 1.

Table 1: Number of course syllabi collected and surveyed in each Engineering department.

\begin{tabular}{|l|r|r|r|r|r|}
\hline & \multicolumn{1}{|l|}{$\begin{array}{l}\text { 1st } \\
\text { Year }\end{array}$} & $\begin{array}{l}\text { 2nd } \\
\text { Year }\end{array}$ & $\begin{array}{l}\text { 3rd } \\
\text { Year }\end{array}$ & $\begin{array}{l}\text { 4th } \\
\text { Year }\end{array}$ & Total \\
\hline Biosystems & 0 & 6 & 13 & 8 & $\mathbf{2 7}$ \\
\hline Civil & 2 & 8 & 9 & 24 & $\mathbf{4 3}$ \\
\hline ECE & 1 & 5 & 12 & 30 & $\mathbf{4 8}$ \\
\hline Mechanical & 1 & 6 & 8 & 26 & $\mathbf{4 1}$ \\
\hline
\end{tabular}

Since there are many streams and specializations that students can take by choosing different electives, no distinction was made between core and elective courses in this study. Table 1 includes the sum total of both types of courses offered by each department.

There is only a small number of first year courses offered by the Faculty of Engineering since all Engineering students take a common core curriculum for first year that includes many courses from other faculties.

\subsection{Syllabi identifying Attribute 7}

Not all of the 159 course syllabi surveyed identified Attribute 7 as a learning outcome for the course. The graph in Figure 1 shows how the number of courses that identify Attribute 7 changes from first to fourth year in each department.

\section{Number of Courses that Identify A7 per year}

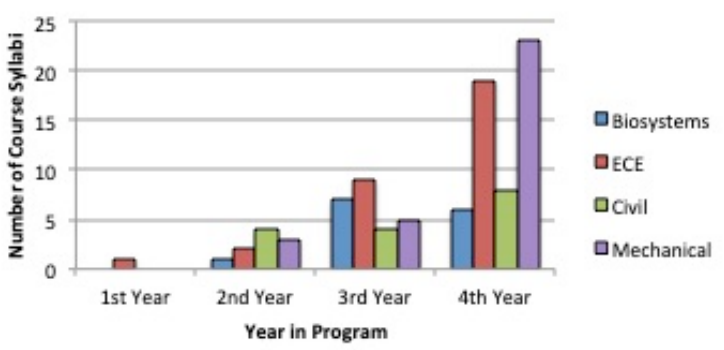

Figure 1: Total number of course syllabi that include Attribute 7.

Overall, the number of courses that identify Attribute 7 increases from second year to fourth year, shown as well in Table 2 . However, due to the larger number of elective course offerings in later years, students are not necessarily taking more courses with communications as a learning outcome.

Table 2: Number of courses in each Engineering department that identified Attribute 7 as a learning outcome.

\begin{tabular}{|l|r|r|r|r|r|}
\hline & \multicolumn{1}{|l|}{$\begin{array}{l}\text { 1st } \\
\text { Year }\end{array}$} & $\begin{array}{l}\text { 2nd } \\
\text { Year }\end{array}$ & $\begin{array}{l}\text { 3rd } \\
\text { Year }\end{array}$ & $\begin{array}{l}\text { 4th } \\
\text { Year }\end{array}$ & Total \\
\hline Biosystems & 0 & 1 & 7 & 6 & $\mathbf{1 4}$ \\
\hline Civil & 0 & 4 & 4 & 8 & $\mathbf{1 6}$ \\
\hline ECE & 1 & 2 & 9 & 19 & $\mathbf{3 1}$ \\
\hline Mechanical & 0 & 3 & 5 & 23 & $\mathbf{3 1}$ \\
\hline
\end{tabular}

Figure 2 shows the percentage of courses in each year that identify Attribute 7 within each department. In Biosystems Engineering and Mechanical Engineering, the relative number of courses with a communication learning outcome does increase over the course of the program. In fact, in Mechanical Engineering, 88\% of all 4000-level courses include Attribute 7. However, in Electrical and Computer Engineering, the fraction of courses with Attribute 7 is highest in third year and, in Civil Engineering, the 
percentage of these courses decreases from second to fourth year.

\section{Percentage of Courses that Identify A7 per department}

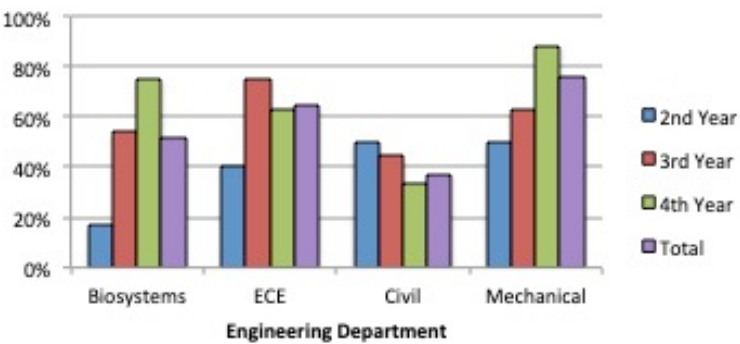

Figure 2: Percentage of courses per year in each department that include Attribute 7.

\subsection{Competency Levels}

Each course syllabi also specified the competency level at which students are expected to perform. Across the departments, two different scales were used, Bloom's Taxonomy and the CEAB I,D,A scale. Table 3 shows how the levels of these two scales are related.

Table 3: CEAB Attribute Competency Levels Conversion

\begin{tabular}{|l|l|l|}
\hline CEAB Level & \multicolumn{2}{|l|}{ Bloom's Taxonomy } \\
\hline \multirow{2}{*}{ Introductory } & 1 & Knowledge \\
\cline { 2 - 3 } & 2 & Comprehension \\
\hline \multirow{2}{*}{ Developing } & 3 & Application \\
\cline { 2 - 3 } & 4 & Analysis \\
\hline Advanced & 5 & Synthesis \\
\hline
\end{tabular}

As shown in Figure 3, Civil, Electrical and Computer, and Mechanical Engineering each have courses in which Attribute 7 is assessed at the "Introductory" level, and all departments have courses with Attribute 7 assessed at the "Developing" and "Advanced" levels.

Interestingly, as Figure 3 shows, the Electrical and Computer Engineering and Mechanical Engineering departments have the highest number of courses at the "Developing" level (35\% and $49 \%$ of all of their course syllabi, respectively).

\section{Number of Courses with A7 at each CEAB level}

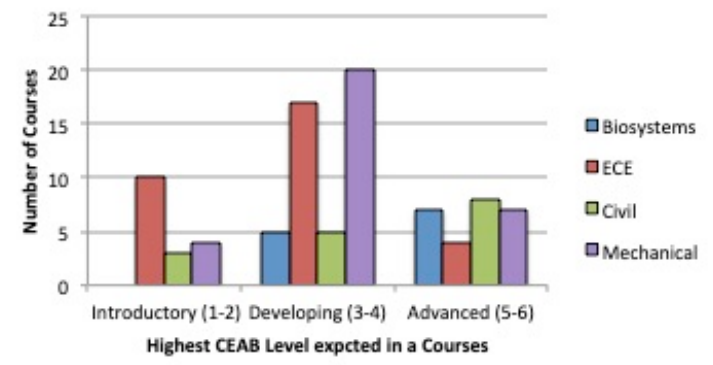

Figure 3: Number of courses in each department that identify Attribute 7 at each IDA level.

All in all, there was an increase in the number of courses that identified Attribute 7 as a learning outcome in 2014 and 2019, as shown below:

Number of Courses that Identify A7

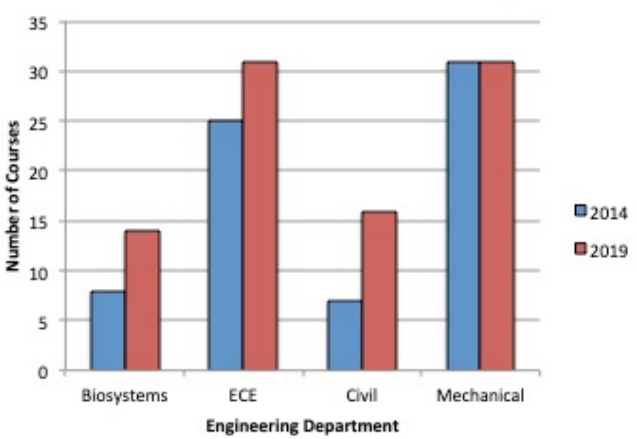

Figure 4: Comparison of the number of courses in Engineering that identified Attribute 7 as a learning outcome in 2014 and 2019.

\subsection{Assessing Attribute 7}

Some course syllabi specifically identified the assignment genre where Attribute 7 would be assessed. When course syllabi did not identify where or how Attribute 7 would be assessed, we looked for assessment categories in which communication skills could reasonably be present. The most common of these assessment tools were labs, projects and generic "assignments." For the purposes of this study, less common assessment tools, such as debates, oral presentations and research reports, were grouped together into the "other" category. As well, tests, quizzes and exams were not considered to be assessment tools for Attribute 7 in this study.

The number of courses with each assignment type in each year of study, across all 
four departments in Engineering, is shown in Figure 5. Some courses used more than one type of assignment.

\section{Assignment types by year in Engineering}

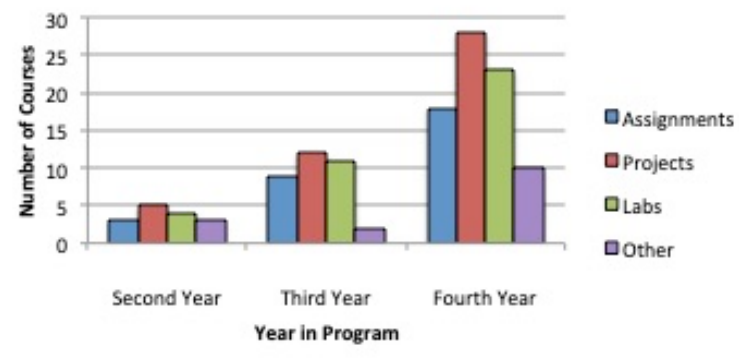

Figure 5: Assignment types by year in Engineering in courses that identify Attribute 7.

There are more courses offered in each department, particularly electives, as students move from second year to fourth year. Correspondingly, the number of courses that include assignments, labs and projects as assessment tools also increases from second year to fourth year. However, the relative number of courses that require students to submit assignments, labs or projects remains relatively steady from second year to fourth year in the faculty. As shown in Figure 6, in any given year of the program, about one-third of courses with Attribute 7 require assignments (30-36\%). Labs are slightly more prevalent (40-44\%), and projects are the most common assessment tool (48-50\%). The "other" assessment category varies most widely from year to year, although the capstone courses required by each department in fourth year all included at least one assessment in the "other" category.

\section{Percent of Engineering Courses with A7 that use each Assessment Type}

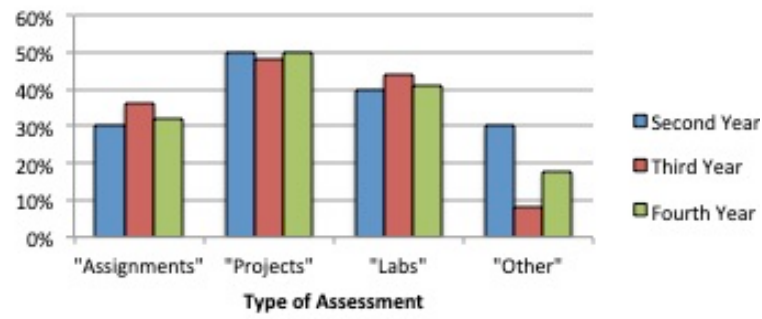

Figure 6: Percentage of courses that identify Attribute 7 and that use each assessment tool in each year of the Engineering program.
How Attribute 7 is assessed differs across the departments. While all departments use assignments, projects and labs as assessment tools, the number and weighting of these assessments varies between the departments. Figure 7 shows the number of assignments, labs and projects that these four departments use; also shown is the percentage of the grade given for these assignments:

\section{Percentage of Final Grade Given to each Assessment Type in A7 Courses \\ 口Biosystems aECE 口Civil םMechanical}

Assignments

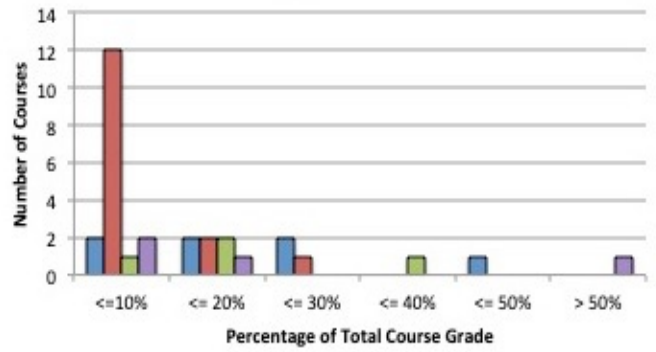

Projects

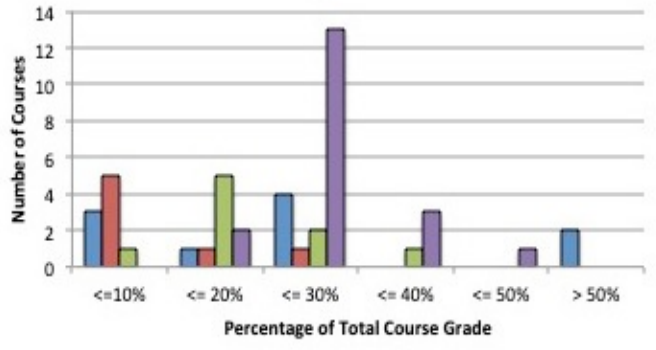

Labs

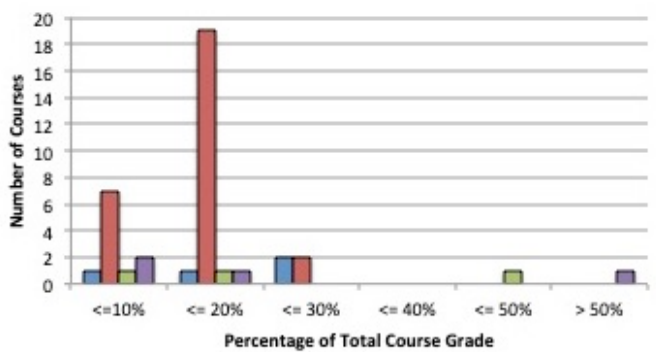

Figure 7: Percentage of the final grade given to each assessment type in courses that identify Attribute 7.

\subsection{Notable Trends}

A few trends stand out from this analysis. Assignments and labs are used most 
often in the Electrical \& Computer Engineering department, and usually account for $20 \%$ or less of the final grade in these courses. The Mechanical Engineering department has the largest number of courses that include projects, most of which are worth over $30 \%$ of the final grade. Mechanical Engineering also has the largest number of courses that contain an assessment worth at least $50 \%$ of a student's final grade. There are 13 such courses in the faculty, six of which are offered by the Mechanical Engineering department.

The first iteration of this study of Attribute 7 was conducted on the Engineering course syllabi available in 2014. Figures 8 shows how the ratio of courses that identify Attribute 7 as a learning outcome has changed over this period.

\section{Percentage of Courses that Identify} A7 per Department

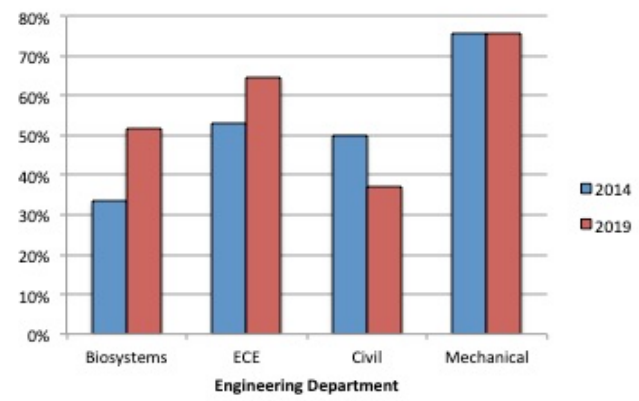

Figure 8: Comparison of the percentage of courses in Engineering that identified Attribute 7 as a learning outcome in 2014 and 2019.

In the Biosystems Engineering and the Electrical and Computer Engineering departments, the number of courses that identified Attribute 7 as a learning outcome increased from 2014 to 2019 . In these departments, the percentage of their courses with Attribute 7 also increased over that time.

The percentage of course syllabi that identified Attribute 7 as a learning outcome decreased in Civil Engineering, even though the absolute number of courses with Attribute 7 in this department increased over the past five years. This discrepancy may be because additional courses, both with and without Attribute 7, were added to the department or made available to the researchers. In the Mechanical Engineering department, both the absolute number of courses and the percentage of courses that identified Attribute 7 remained the same from 2014 to 2019 .

\subsection{OBSERVATIONS AND CONCLUSIONS}

Whereas in the first iteration we were part of a national group of various faculties and departments, this second iteration focused exclusively on the Engineering departments at the University of Manitoba. As such, we now had a far better idea as to what to expect and, perhaps more importantly, what to look for.

Not surprisingly, there were some of the same trends that we had noticed earlier as well as some relatively minor changes. For one thing, the latest round of course syllabi were more organized, though they still did not specify what these generic "assignments" or "projects" were. But in 2019 more courses identified Attribute 7 as a learning outcome, and the later years in the programs tended to give a greater weighting to Attribute 7. Likewise, although some syllabi still used Bloom's taxonomy, in general the I, D, A model was adopted.

In many ways, the two Engineering Communication courses offered in second year at the University of Manitoba continue to represent all things related to Attribute 7, but the trends shown here are noteworthy. As a faculty, we are working toward a more cumulative approach whereby courses offered later in a program will build upon the foundation that these earlier communication courses in particular and Engineering courses in general have already laid.

Therefore, we as a faculty continue to work towards meeting our stakeholders' expectations as well as the expectations for our programs: namely, that we emphasize communication skills; that we build upon a solid foundation in communication skills; and that we recognize that communication, and writing in particular, are practice-based skills that require scaffolding and iteration.

\section{ACKNOWLEDGEMENTS}

The original national study was made possible by a grant from the Social Sciences and 
Humanities Research Council of Canada (SRG RES0006514). We would like to thank Dr. Roger Graves, Professor, English and Film Studies, and Director, Writing Across the Curriculum, University of Alberta. Finally, we would also like to thank our Dean, Dr. Jonathan Beddoes; our Associate Dean (Design Education), Dr. Marcia Friesen; and the departments who so willingly allowed us to collect their course syllabi.

\subsection{References}

[1] Ferens, K, J.Seniuk Cicek, Nariman Sepehri, Witold Kinsner, J.P. Burak, A. Parker, D. McNeill, D. Ruth, I. Jeffrey, N. Godavari, and S. Ingram, "Industry Forum III: Towards a common language," in Proc. CEEA Canadian Engineering Education Conference. (Canmore, AB; 8-11 June), 6 pp., 2014.

[2] Parker, A. and K. Marcynuk, "Undergraduate writing assignments in Engineering: Teaching communication skills (Attribute 7)," in Proc. CEEA Canadian Engineering Education Conference. (Halifax, N.S., 19-22 June), 2016.

[3] Paretti, M.C., "Communication in professional practice: Designing assignments to develop Engineering professionals," in ASEE Southeast Section Conference, 2005 (The University of Tennessee: Chattanooga TN; 3-5 April), no pp., 2005.

[4] Paretti, M.C and L.D. McNair, "Introduction to the Special Issue on communication in Engineering curricula: Mapping the landscape," IEEE Transactions on Professional Communication, v.51, n.3, pp.238-241, 2008.

[5] Reave, L., "Technical Communication instruction in Engineering schools: A survey of top-ranked U.S. and Canadian programs," Journal of Business and Technical Communication, v.18, no.4, pp.452-490, 2004. 